\title{
PENERAPAN METODE USABILITY TESTING PADA VISUALISASI PEMBELAJARAN PROTOKOL SPANNING TREE
}

\author{
Sandita A. Surbakti ${ }^{(1)}$ \\ Sandita_as@yahoo.com
}

\author{
Joko Purwadi $^{(2)}$ \\ jokop@ukdw.ac.id
}

\author{
Nugroho Agus Haryono ${ }^{(3)}$ \\ cnuq@ukdw.ac.id
}

\begin{abstract}
Abstraksi
Topologi ganda sangat dibutuhkan untuk meningkatkan availabilitas suatau jaringan dengan mencegah tidak bisa diaksesnya suatu bagian jaringan karena gagalnya komunikasi dalam suatu titik. Namun demikian topologi ganda dapat memunculkan permasalahan looping frame yang bisa menyebabkan kepadatan lalu lintas paket. Protokol Spanning Tree yang berjalan di Layer 2 dikembangkan untuk mengatasi munculnya looping pada topologi ganda. Protokol ini menggunakan mekanisme pengaturan port-port yang berperan dalam topologi ganda dalam status forwarding dan blocking (alternatif forward) secara administratif.

Visualisasi Pembelajaran Protokol Spanning Tree ini dibuat untuk menjadi salah satu media pembelajaran yang menyajikan materi Protokol Spanning Tree dalam bentuk animasi, soal-soal latihan, dan studi kasus yang membantu dalam proses pemahaman dan pembelajaran Protokol Spanning Tree. Untuk mengukur tingkat usabilitas program ini, digunakan beberapa metode Usability Testing yang ada, yaitu: compatibility, consistency, flexibility, learnability, perceptual limitation, dan minimal action.

Dari hasil penelitian terhadap mahasiswa kategori belum pernah belajar Protokol Spanning Tree sebelumnya diperoleh nilai Compatibility: 81.09\%, Consistency: 75.64\%, Flexibility: 76.73\%, Learnability: 77.45\%, Minimal Action: $74.55 \%$, dan Perceptual Limitation: $77.82 \%$. Sedangkan Penelian terhadap mahasiswa yang sudah pernah belajar Protokol Spanning Tree diperoleh nilai Compatibility: 78.67\%, Consistency: 74.67\%, Flexibility: 74.22\%, Learnability: 72.89\%, Minimal Action: $75.11 \%$, dan Perceptual Limitation: $80 \%$.
\end{abstract}

Kata Kunci : Protokol Spanning Tree, Metode Usability Testing, Switch, Compatibility, Consistency, Flexibility, Learnability, Perceptual Limitation, Minimal action, frame Looping.

\section{Pendahuluan}

Teknologi informasi dan komunikasi banyak dimanfaatkan dalam dunia pendidikan. Mulai dari presentasi, tutorial, animasi, simulasi pembelajaran dan lain sebagainya. Teknologi

\footnotetext{
${ }^{1}$ Teknik Informatika, Fakultas Teknologi Informasi,Universitas Kristen Duta Wacana

${ }^{2}$ Teknik Informatika, Fakultas Teknologi Informasi Univeristas Kristen Duta Wacana

${ }^{3}$ Teknik Informatika, Fakultas Teknologi Informasi,Universitas Kristen Duta Wacana
} 
ini telah mampu mengintegrasikan berbagai jenis media ke dalam satu model pembelajaran. Salah satu model pembelajaran yang digunakan untuk menyampaikan materi yaitu melalui media pembelajaran yang memvisualisasikan materi Protokol Spanning Tree. Protokol Spanning Tree digunakan untuk menghindari loop pada suatu topologi ganda.

\subsection{Perumusan Masalah}

Permasalahan yang dibahas dalam tulisan ini adalah:

a. Bagaimana cara memvisualisasikan materi Protokol Spanning Tree ke dalam bentuk animasi pembelajaran

b. Seberapa baik tingkat usabilitas program ini diukur menggunakan metode Usability Testing.

\subsection{Metode Penelitian}

a. Studi Pustaka

Studi pustaka dilakukan dengan mengumpulkan informasi dan mempelajari semua sumber referensi yang dapat mendukung penelitian Visualisasi Pembelajaran Protokol Spanning Tree, baik itu dari buku, jurnal, artikel ataupun dari internet.

b. Implementasi

Penulis mengimplementasikan Metode Usability Testing pada Aplikasi Pembelajaran Visualisasi Pembelajaran Protokol Spanning Tree yang digunakan untuk mengetahui apakah aplikasi tersebut dapat dipahami oleh pengguna.

\section{Teori Pendukung}

\subsection{Protokol Spanning Tree}

Menurut Lewis (2008:244), Protokol Spanning Tree (STP) dikembangkan oleh Radia Perlman dan dipublikasikan dalam standar IEEE 802.1D pada tahun 1990. STP digunakan untuk menghindari terjadinga loop pada jaringan dengan topologi ganda. Masih menurut Lewis (2008:244), STP bekerja berdasarkan identitas Bridge/Switch. Identitas bridge (BridgeID) terdiri dari nilai prioritas dan MAC Address dari Switch. BridgeID digunakan untuk memilih salah satu switch menjadi root bridge. Jika root bridge telah dipilih, maka switch-switch yang lain harus mempelajari port-port mana yang memiliki jalur terbaik menuju root bridge. Langkah-langkah yang dilakukan dalam Algoritma Protokol Spanning Tree diberikan berikut ini.

a. Melakukan pemilihan root bridge 
Proses pemilihan root bridge dijelaskan pada Gambar 1. Semua switch saling tukar menukar BridgeID masing-masing. Switch yang memiliki BridgeID yang paling kecil akan menjadi root bridge.

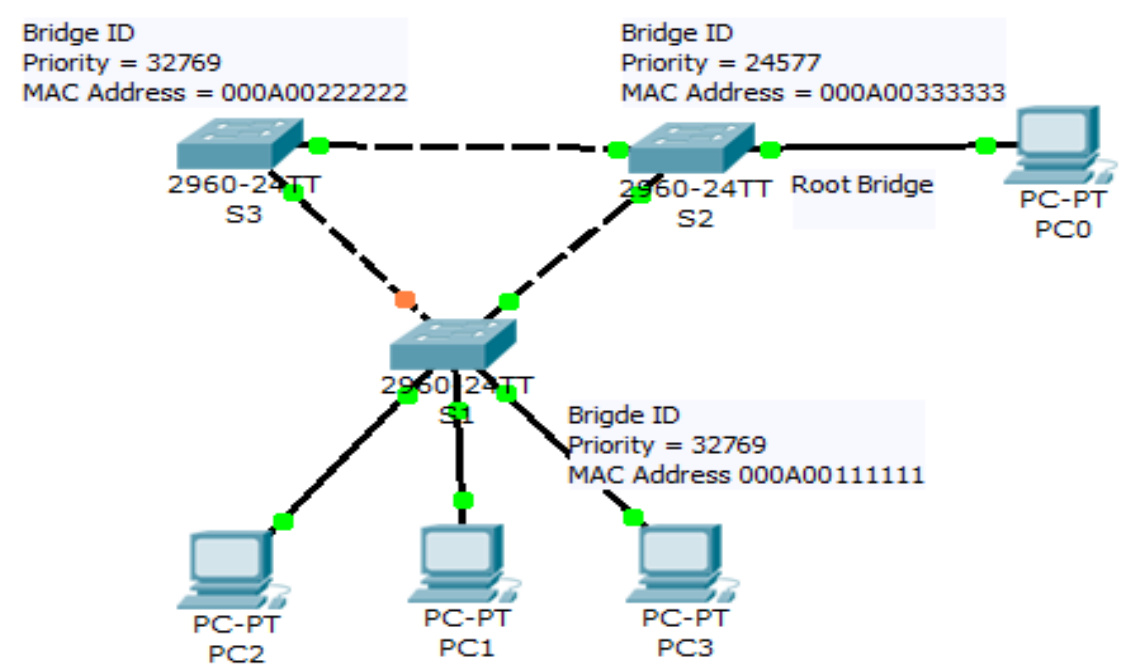

Gambar 1. Pemilihan Root Bridge Berdasarkan Priority yang Paling Kecil Dikutip dari Lewis (2008). LAN Switching and Wireless, hlm.249.

b. Melakukan pemilihan root port

Setelah salah satu switch menjadi root bridge, maka proses selanjutnya adalah pemilihan root port. Pemilihan root port yang dijelaskan pada Gambar 2., dilakukan berdasarkan pada port yang memiliki jalur dengan biaya terendah menuju switch yang menjadi root bridge.

c. Melakukan pemilihan designated port

Pemilihan designated port dilakukan dengan menggunakan mekanisme bahwa setiap segmen dalam jaringan hanya mempunyai designated port. Parameter yang digunakan dalam menentukan designated port adalah jalur yang memiliki biaya terendah menuju root bridge. Pada Gambar 2.2 menjelaskan tentang proses pemilihan designated port. Jika port pada setiap switch memiliki biaya yang sama maka switch akan menggunakan MAC Address yang paling kecil untuk menentukan port yang akan menjadi designated port. 


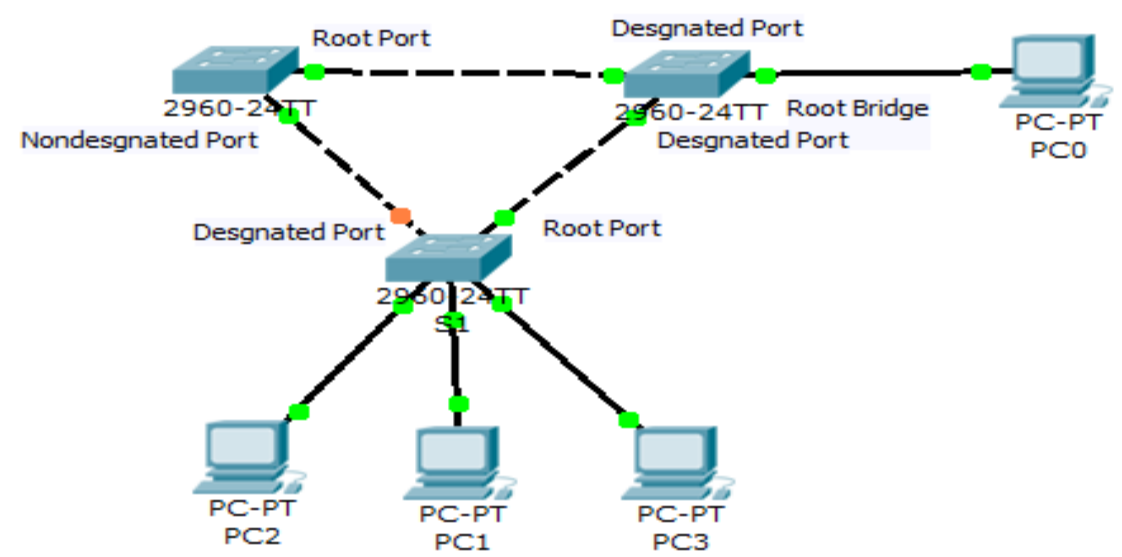

Gambar 2. Pemilihan Root Port, Designated Port dan Non-designated Port Dikutip dari Lewis (2008). LAN Switching and Wireless, hlm.264.

d. Melakukan pemilihan non-designated port

Pemilihan non-designated port pada Gambar 2. dilakukan berdasarkan pada port yang bukan merupakan root port dan designated port. Status port ini akan menjadi blocking untuk mencegah loop.

\subsubsection{Bridge ID}

Bridge ID digunakan untuk menentukan switch yang akan dijadikan root bridge. Komponen dari Bridge ID yang dijelaskan pada Gambar 3. Adalah Bridge Priority yang terdiri dari 2 bytes yang berisi bilangan desimal dan MAC Address yang terdiri dari 8 bytes yang berisi bilangan heksadesimal (Lewis, 2008).

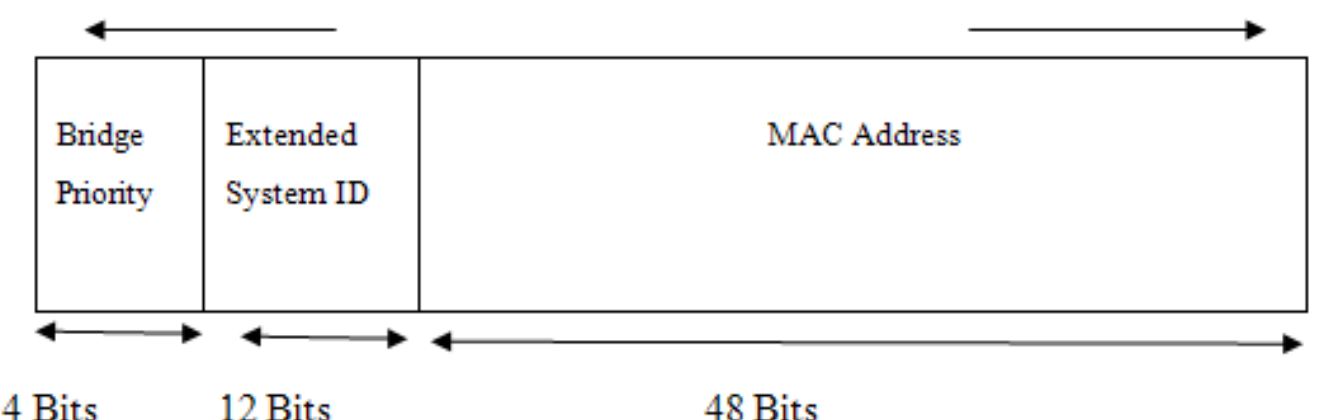

Gambar 3. Bridge ID

Dikutip dari Lewis (2008). LAN Switching and Wireless, hlm.249.

\subsubsection{Path Cost}

Informasi path cost (biaya dari jalur) yang dijelaskan pada Tabel 1. diperoleh dengan cara menjumlahkan masing-masing biaya dari setiap port pada jalur yang menuju root bridge. 
Tabel 1. Daftar Biaya Berdasarkan Jenis Kabel yang Digunakan

Dikutip dari Lewis (2008). LAN Switching and Wireless, hlm.250.

\begin{tabular}{lll}
\hline $\begin{array}{l}\text { Link } \\
\text { Speed }\end{array}$ & Cost(Revised IEEE Specification) & Cost(PreviousIEEE Specification) \\
\hline $10 \mathrm{Gbps}$ & 2 & 1 \\
\hline $1 \mathrm{Gbps}$ & 4 & 1 \\
\hline $100 \mathrm{Gbps}$ & 19 & 10 \\
\hline $10 \mathrm{Mbps}$ & 100 & 100 \\
\hline
\end{tabular}

\subsubsection{Status Port Protokol Spanning Tree}

Setiap port yang telah menjadi root port, designated port, dan non-designated port akan merubah statusnya. Root port dan designated port akan merubah statusnya menjadi forwarding, sedangkan non-designated port akan merubah statusnya menjadi blocking. Fungsi dari status forwarding yaitu untuk meneruskan frame yang disebarkan pada topologi loop, sedangkan fungsi dari status blocking yaitu tidak meneruskan frame untuk mencegah terjadinya loop (Lewis,2008). Ada beberapa status port selain forwarding dan blocking, status port tersebut yaitu :

a. Learning.. Suatu port merubah statusnya menjadi learning ketika akan memperbaharui tabel MAC Address.

b. Listening. Suatu port akan merubah statusnya menjadi listening ketika port tersebut menerima informasi berupa Bridge ID dari switch lain.

c. Disabled. Suatu port menjadi disabled karena port tersebut tidak terlibat pada proses spanning tree atau ketika port tersebut mati.

\subsection{Usability Testing}

Prinsip-prinsip yang digunakan untuk mengukur seberapa usable suatu sistem yaitu compatibility, consistency, flexibility, learnability, minimal action, dan perceptual limitation (Lin, Choong, \& Salvendy, 1997) .

a. Compatibility. Kompatibilitas mengacu pada suatu fenoma bahwa respon subjek lebih cepat dan lebih akurat dan kinerjanya tidak akan terhambat jika informasi yang ditampilkan dari suatu sistem kompatibel. 
b. Consistency. Sistem yang memberikan kepuasan kepada pengguna harus mempertimbangkan dua elemen, yaitu konsistensi internal dan konsistensi eksternal. Konsistensi internal merupakan konsistensi dalam sebuah sistem, sedangkan konsistensi eksternal merupakan konsistensi diantara berbagai sistem.

c. Flexibility. Antarmuka sistem harus bisa beradaptasi dengan kebutuhan pengguna dan perbedaan tingkat keterampilan dan kemampuan masing-masing pengguna.

d. Learnability. Sistem yang dibangun harus mudah dipelajari oleh pengguna, sesuai cara pengguna belajar yaitu dengan cara menghafal, belajar dengan cara memahami dan belajar dengan cara eksplorasi. Sistem yang terorganisasi akan dapat membantu pengguna dalam memahami sistem tersebut.

e. Minimal Action. Sistem yang dibangun harus memberikan efisiensi waktu ketika pengguna menggunakan atau mengoperasikan sistem tersebut.

f. Perceptual Limitation. Sistem memiliki batasan-batasan dari setiap elemen yang berbeda kemudian dikelompokkan. Salah satu batasan-batasan tersebut yaitu pertimbangan penggunaan warna yang familiar dengan pengguna.

\section{Analisis}

Visualisasi pembelejaran Protokol Spanning Tree (STP) ini dibuat dalam tiga halaman, yaitu: halaman untuk tutorial guna memberikan visualisasi materi protokol spanning tree, halaman latihan guna memberikan soal-soal latihan untuk menguji hasil belajar, dan halaman studi kasus guna melatih pemahaman mengenai materi dengan menggunakan kasus-kasus yang ada.

\subsection{Halaman Utama Aplikasi Pembelajaran Protokol Spanning Tree}

Pada halaman menu yang terdapat pada Gambar 4, terdiri dari Animasi Fungsi STP yang terdapat Tombol On dan Off. Proses STP yang terdiri dari Tombol Root Bridge, Root Port, Designated Port, dan Non-designated Port. Selain itu, pada halaman utama terdapat Tombol Ujian dan Studi Kasus. 


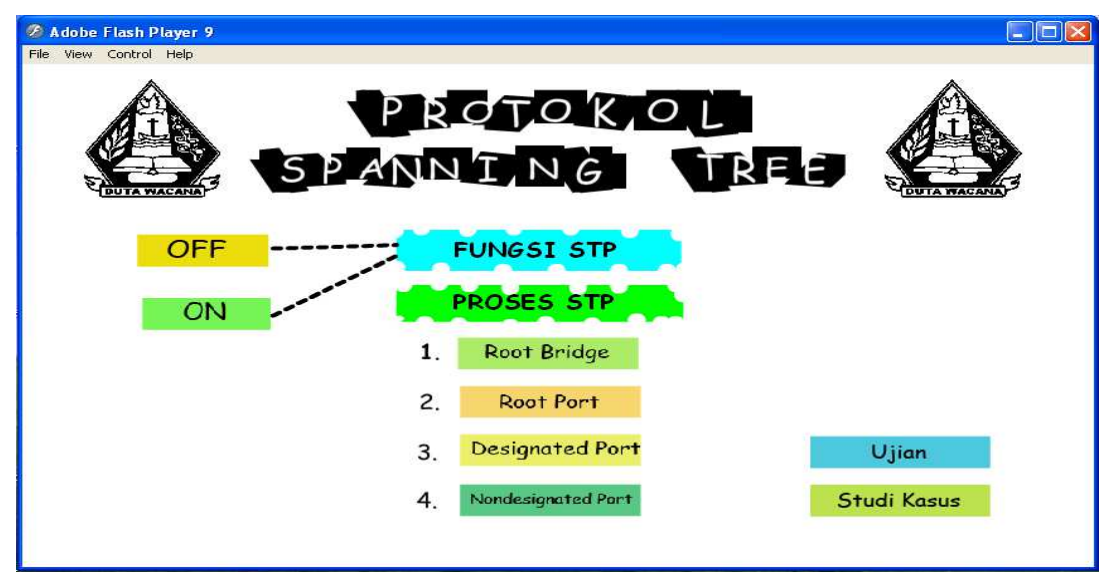

Gambar 4. Halaman Menu

Pada menu Fungsi STP diberikan visualisasi yang menjelaskan fungsi STP. Pembelajaran dilakukan dengan membandingkan perjalanan frame jika STP dimatikan (OFF) dengan perjalanan frame jika STP dihidupkan (ON). Pada menu Proses STP diberikan visualisasi lengkap dan detil dari proses-proses yang dilakukan untuk menjalankan STP sampai dengan berhasil, yaitu proses pemilihan root bridge, pemilihan root port, pemilihan designated port dan pemilihan non-designated port. Pada menu Ujian akan menampilkan soal-soal latihan yang harus dijawab oleh pengguna dengan penilaian yang dilakukan oleh sistem. Pada menu Studi Kasus akan menampilkan visualisasi kasus-kasus STP untuk mempertajam pemahaman pembelajar dalam belajar STP.

\subsection{Soal-Soal Latihan Protokol Spanning Tree}

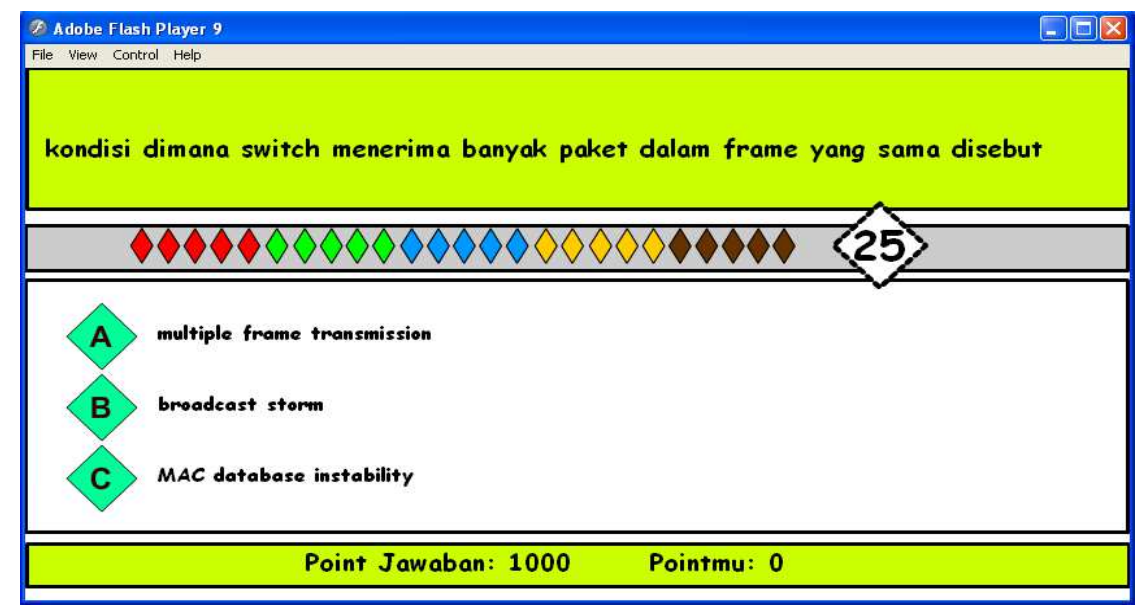

Gambar 5. Halaman Soal Protokol Spanning Tree (STP) 
Halaman soal Protokol Spanning Tree menampilkan sepuluh soal-soal spanning tree. Pada Gambar 3.2 menampilkan waktu soal yang memaksa pengguna untuk menyelesaikan soal dengan cepat, pilihan-pilihan jawaban dari soal Protokol Spanning Tree, "Point Jawaban" yang berkurang ketika waktu soal mulai berkurang, dan "Pointmu" yang menampilkan poin pengguna

\subsection{Studi Kasus Protokol Spanning Tree}

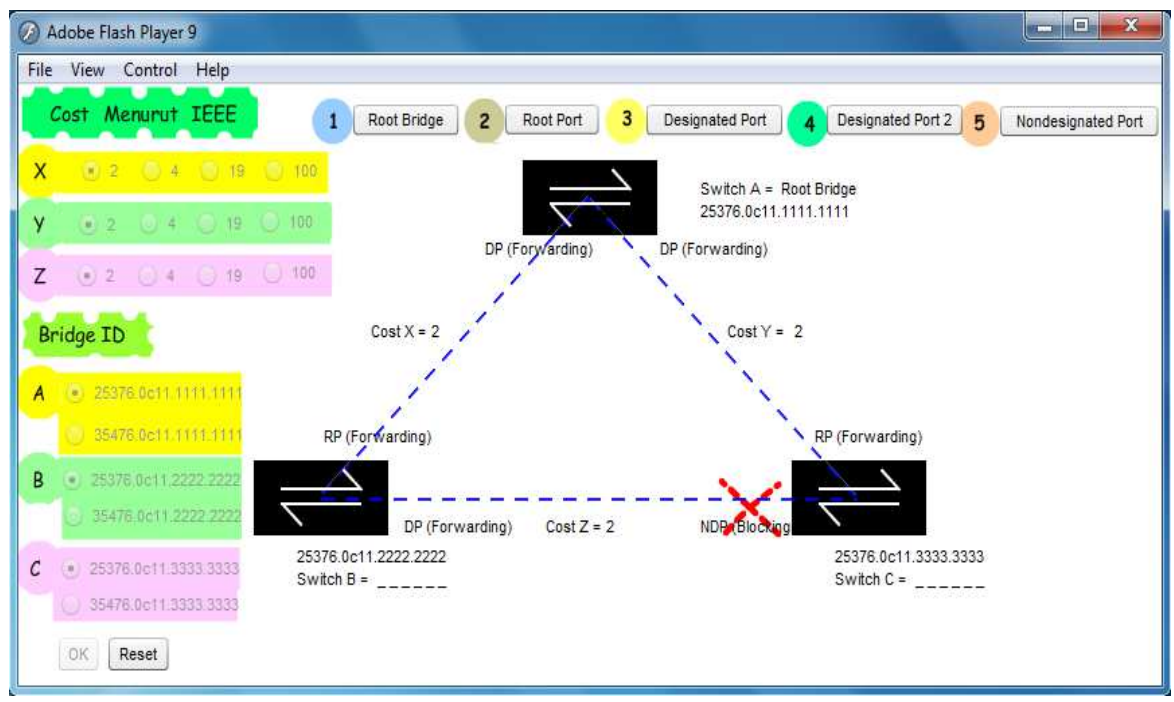

Gambar 6. Halaman Soal Protokol Spanning Tree (STP)

Halaman studi kasus Protokol Spanning Tree pada Gambar 3.3 menampilkan tiga switch yang saling terhubung membentuk topologi loop. Pengguna dapat memilih Bridge ID dari switch-switch yang ada dan juga bisa memilih cost dari jalur yang ada.

\subsection{Rangkuman Hasil Uji Usability Tahap I dan II}

Untuk mengukur tingkat usabilitas program yang dibuat, maka dilakukan survey kuesioner kepada beberapa mahasiswa kategori belum pernah belajar STP dan kepada para mahasiswa yang pernah belajar STP. Kuesioner Tahap I dilakukan untuk melakukan perbaikanperbaikan program sesuai masukan dari para pengisi kuesioner. Kuesioner Tahap II dilakukan setelah program diperbaiki. Hasil rangkuman uji usability Tahap I dan II diberikan dalam Tabel 3.1 .

Tabel 2. Rangkuman Hasil Uji Usability Tahap I dan II Kategori Belum Pernah dan Pernah Belajar Protokol Spanning Tree 


\begin{tabular}{|c|r|r|r|r|}
\hline \multirow{2}{*}{} & \multicolumn{3}{|c|}{ Usability Test Tahap I } & \multicolumn{2}{c|}{ Usability Test Tahap II } \\
\cline { 2 - 5 } & Belum Pernah & \multicolumn{1}{|c|}{ Pernah } & Belum Pernah & \multicolumn{1}{c|}{ Pernah } \\
\hline Compatibility (\%) & 60 & 64.89 & 81.09 & 78.67 \\
\hline Consistency (\%) & 56.73 & 61.33 & 75.64 & 74.67 \\
\hline Flexibility (\%) & 57.09 & 62.67 & 76.73 & 74.22 \\
\hline Learnability (\%) & 60.73 & 60.44 & 77.45 & 72.89 \\
\hline Minimal Action (\%) & 59.27 & 59.11 & 74.55 & 75.11 \\
\hline Perceptual Limitation (\%) & 64.36 & 62.67 & 77.82 & 80 \\
\hline
\end{tabular}

\subsection{Rangkuman Hasil Uji Usability pada Soal-Soal Latihan Protokol Spanning Tree}

Untuk mengukur tingkat keberhasilan pemahaman pembelajaran, maka dilakukan juga survey untuk menilai prosentase keberhasilan pembelajar dalam menjawab soal-soal yang diberikan dalam halaman Ujian. Hasil rangkuman uji Usability halaman ujian diberikan dalam Tabel 3.2.

Tabel 3. Hasil Uji Usability Soal-Soal Latihan Kategori Belum Pernah dan Pernah Belajar Protokol Spanning Tree

\begin{tabular}{|c|l|c|c|l|c|c|}
\hline NO & $\begin{array}{c}\text { Belum } \\
\text { Pernah } \\
\text { Belajar }\end{array}$ & Poin & $\begin{array}{c}\text { Prosentase } \\
\text { Keberhasilan }\end{array}$ & $\begin{array}{l}\text { Pernah } \\
\text { Belajar }\end{array}$ & Poin & $\begin{array}{c}\text { Prosentase } \\
\text { Keberhasilan }\end{array}$ \\
\hline 1 & Yeni & 6960 & $69.6 \%$ & Andien & 9500 & $95 \%$ \\
\hline 2 & Alril & 7260 & $72.6 \%$ & Dida & 9460 & $94.6 \%$ \\
\hline 3 & Yosua Eko Y & 7780 & $77.8 \%$ & Fiona & 9700 & $97 \%$ \\
\hline 4 & Pebrindanov & 7690 & $76.9 \%$ & $\begin{array}{l}\text { Stefanus } \\
\text { Eki }\end{array}$ & 8980 & $89.8 \%$ \\
\hline 5 & Aji Pramono & 7560 & $75.6 \%$ & Jinki Tona & 9670 & $96.7 \%$ \\
\hline 6 & Haditya & 7890 & $78.9 \%$ & Tabitha & 9100 & $91 \%$ \\
\hline 7 & Amanda & 7980 & $79.8 \%$ & $\begin{array}{l}\text { Richard } \\
\text { F.S }\end{array}$ & 9390 & $93.9 \%$ \\
\hline 8 & Yuridsman & 6800 & $68 \%$ & Griffin & 9650 & $96.5 \%$ \\
\hline 9 & Nelson & 7490 & $74.9 \%$ & Ade & 9280 & $92.8 \%$ \\
\hline
\end{tabular}

\section{Kesimpulan}

1) Pada pengujian usability terhadap mahasiswa kategori belum pernah belajar STP pada Tahap I diperoleh hasil prosentase nilai untuk Compatibility sebesar 60\%, Consistency 
sebesar 56.73\%, Flexibility sebesar 57.09\%, Learnability sebesar 60.73\%, Minimal Action sebesar 59.27\%, dan Perceptual Limitation sebesar 64.36\%. Sedangkan pada Tahap II diperoleh hasil prosentase nilai untuk Compatibility sebesar 81.09\%, Consistency sebesar 75.64\%, Flexibility sebesar 76.73\%, Learnability sebesar 77.45\%, Minimal Action sebesar $74.55 \%$, dan Perceptual Limitation sebesar $77.82 \%$.

2) Pada pengujian usability terhadap mahasiswa kategori pernah belajar STP pada Tahap I diperoleh hasil prosentase nilai untuk Compatibility sebesar 64.89\%, Consistency sebesar 61.33\%, Flexibility sebesar 62.67\%, Learnability sebesar 60.44\%, Minimal Action sebesar $59.11 \%$, dan Perceptual Limitation sebesar $62.67 \%$. Sedangkan pada Tahap II mengalami peningkatan yang baik terhadap aplikasi pembelajaran tersebut yang dinilai dari prosentase nilai dari Compatibility sebesar 78.67\%, Consistency sebesar 74.67\%, Flexibility sebesar 74.22\%, Learnability sebesar 72.89\%, Minimal Action sebesar 75.11\% , dan Perceptual Limitation sebesar $80 \%$.

3) Hasil uji usability soal-soal latihan kepada pengguna yang belum pernah belajar memiliki poin antara 6800 - 7980. Sedangkan pengguna yang pernah belajar Protokol Spanning Tree memiliki poin antara 8980 - 9670. Berdasarkan hasil poin dari soal-soal latihan tersebut dari total poin sebesar 10000, maka dapat disimpulkan bahwa pengguna yang belum pernah belajar dan pernah belajar dapat memahami materi Protokol Spanning Tree pada aplikasi pembelajaran ini.

\section{Daftar Pustaka}

Arsyad, Azhar, 1997 Media Pembelajaran. Jakarta : PT. Raja Grafindo Persada

Choong, Lin, \& Salvendy, 1997, A Proposed Index of Usability: A Method for Comparing The Relative Usability of Different Software Systems. Vol. 16 No. 4/5, 267-278.

Lammle, Todd, 2005, CCNA: Cisco Certified Network Associate Study Guide. Jakarta: Elex Media Komputindo Lewis, Wayne, 2008, LAN Switching and Wireless: CCNA Exploration Companion Guide.USA: Cisco Press. Preece, Roger et.al., 2002, Beyond Human-Computer Interaction. John Wiley \& Sons,inc. Pp 279-313. 